\title{
ELECTRICAL AND PHOTOELECTRICAL CHARACTERISTICS OF $c$-Si/POROUS-Si/CdS HETEROJUNCTIONS
}

H. M. Mamedov, A. Kukevecz, Z. Konya, K. Kordas, S. I. Shah, V. U. Mamedov, Kh. M. Ahmedova, V. J. Mamedova, R. M. Rzaev, Sh. A. Shamilova, E. A. Khanmamedova, and L. E. Agazade

Depending on the sizes of the CdS crystallites and silicon pores, electrical and photoelectrical characteristics of $\mathrm{c}-\mathrm{Si} /$ porous-Si/CdS heterojunctions prepared by electrochemical deposition and anodization, respectively, are studied. The optimal pore size $(10-16 \mathrm{~nm})$ is determined, which provides the maximum photoelectric conversion efficiency $(7.71 \%)$ of heterojunctions.

\section{INTRODUCTION}

Thin film $p(n)$-Si/CdS heterojunctions are promising candidates for use in photovoltaics [1-3]. This is due to the fact that the use of wide-gap semiconductors as an optical window in silicon-based heterojunctions to some extent allows minimizing the loss of free charge due to the surface recombination. However, a significant difference between the lattice constants of silicon and CdS (about 7\%) stimulates the formation of surface states at the interface. Although replacing cadmium sulfide with ternary $\left(Z_{1-x} C d_{x} S\right)$ or quaternary $\left(\mathrm{Zn}_{1-x} \mathrm{Cd}_{x} \mathrm{~S}_{1-y} \mathrm{Se}_{y}\right)$ semiconductors made it possible to reduce the mismatch between the lattice constants of the contacting materials, it was still not possible to achieve sufficient efficiency of photoelectric conversion of heterojunctions due to the high refractive index of silicon [4, 5]. As reported in [6-11], the use of porous silicon as an intermediate layer between the absorber and buffer allows to solve problems associated not only with the lattice mismatch between the contacting materials, but also with the surface reflection associated with the refractive index of silicon.

Thin CdS films were prepared by various methods [12-16], which have their own drawbacks and difficulties. Among these methods, the method of electrochemical deposition allows one to prepare films of various structures and surface morphology by a simpler cycle [4, 5, 17-19].

The purpose of this work is to improve the electrical and photovoltaic characteristics of $p$-Si/CdS heterojunctions by forming a porous silicon (PS) layer on the surface of the crystalline silicon.

\section{EXPERIMENT}

For the fabrication of heterojunctions, $p$-type single-crystal (100) silicon plates (c-Si) were used as the substrates (with the resistivity of $2.5 \Omega \cdot \mathrm{m}$ and thickness of $0.2-0.3 \mathrm{~mm}$ ). Before anodization, the $c$-Si surface was cleaned in an aqueous solution of $\mathrm{HF}$, washed with deionized water at a temperature of $80^{\circ} \mathrm{C}$ and ethyl alcohol, and then, dried in air. Anodization of the $c$-Si substrate surface was carried out in a Teflon chamber with a platinum cathode. For the formation of porous silicon, an HF:ethanol (1:1) solution was used. The anodization voltage, current density, and anodization time were $30 \mathrm{~V}, 40-70 \mathrm{~mA} / \mathrm{cm}^{2}$, and 30-1800 s, respectively. Depending on the values of the anode current and anodization time, PS layers with the pore sizes of $8-70 \mathrm{~nm}$ were obtained on the $c$-Si surface. 
After the formation of PS layer, the samples were immersed in ethyl alcohol, dried in air, and placed in

an electrochemical bath for deposition of nanostructured $\mathrm{CdS}$ films. Electrochemical deposition of $\mathrm{CdS}$ films on the $c$-Si/PS substrates (with the pore sizes of 7.4,10, and $30 \mathrm{~nm}$ ) was carried out at a temperature of $80^{\circ} \mathrm{C}$ in an aqueous solution containing cadmium $\left(\mathrm{CdCl}_{2}\right)$ and sodium $\left(\mathrm{Na}_{2} \mathrm{~S}_{2} \mathrm{O}_{3}\right)$ salts. Cyclic voltammetry based on obtaining and decoding the current-voltage dependences of the polarized electrode-electrolyte solution interface, was used to control electrochemical reactions in $\mathrm{CdCl}_{2}$ and $\mathrm{Na}_{2} \mathrm{~S}_{2} \mathrm{O}_{3}$ solutions, and then, in their combined solution with the same concentration and $\mathrm{pH}$. Cyclic voltammograms were scanned in the potential range from 1.2 to $-1.2 \mathrm{~V}$ with the graphite (or $\mathrm{Ag} / \mathrm{AgCl}$ ) electrodes. Depending on the deposition time and pore size of the substrate, the $0.2-0.6 \mu \mathrm{m}$ thick CdS films with various surface morphologies were deposited.

Indium with an area of $\sim 1 \mathrm{~cm}^{2}$ in grid form was used as an electrical contact to $\mathrm{CdS}$, and aluminum was used for the ohmic contacts to the $c$-Si plates.

\section{RESULTS AND DISCUSSION}

The morphologies of the PS and CdS films were studied with a scanning electron microscope (SEM) of the ZEISS Gemini 300 SEM type. It has been established that the size and shape of pores directly depend on the anodization current density, namely, an increase in the current density leads to an increase in the resulting pore size and significant leveling of the surface between the pores. Despite the fact that the anodization voltage and time change the depth and shape of the pores, as can be seen from Table 1, these anodization parameters have little effect on the pore sizes. Figure $1 a$ shows a SEM image of the surface of PS with the pore sizes of $10-16 \mathrm{~nm}$.

SEM images show that by choosing the pore size of silicon, one can control the crystallite size of nanostructured CdS films deposited on $c$-Si/PS substrates. Films deposited on the PS1 substrates possess microstructural morphology. The grain sizes range from 20 to $70 \mu \mathrm{m}$. When the PS2 is used as substrate, the size of nanoparticles decreases, and the nanoscale grains are uniformly distributed on the surface (Fig. 1b). The particle size determined by SEM was $80-190 \mathrm{~nm}$. As the pore size increases to $30 \mathrm{~nm}$ (PS3), the CdS films exhibit nano-texture, in which the grain sizes differ significantly from each other, which indicates an irregular grain growth rate.

The electrical and photoelectrical properties of heterojunctions were studied depending on the crystallite and pore size. Measurement of the stationary current-voltage characteristics (I-V characteristics) made it possible to establish that the heterojunctions under study possess pronounced rectification properties. It is established that the value of the rectification coefficient $(K)$ determined at $U=1 \mathrm{~V}$ and the current passage mechanism depend on the sizes of pores and crystallites. Figure $2 a$ shows the $I-V$ characteristics of heterojunctions with various pore sizes of silicon (PS1, PS2, and PS3). The direction of rectification corresponds to the positive polarity of the external voltage on $c$-Si. As can be seen from Fig. 2, with an increase in the pore size from 8-11 nm (PS1) to 10-16 nm (PS2), an increase in rectification is observed from 82 to 1100 at $U=1 \mathrm{~V}$. A further increase in the pore sizes (for PS3) leads to sharp decrease in the rectification coefficient $(K=30-40)$.

It is assumed that the change in the values of the rectification coefficient depending on the pore size is associated with oxygen (or nitrogen) molecules. To remove the excess water from the pores and films, the heterojunctions were dried in air immediately after the deposition. In this case, oxygen molecules adsorbed on the surface of $\mathrm{CdS}$ films and diffusing later into the pores of silicon create acceptor states in the junction 
region and thus, increase the recombination activity. It is established that the degree of adsorption depends on the pore size. To confirm this fact, the heterojunctions were heated in vacuum at $50-70^{\circ} \mathrm{C}$, and the $I-V$ characteristics were also measured in vacuum (Fig. $2 b$ ). It can be seen from the figure that the rectification in heterojunctions with PS1 and PS2 practically did not change. However, rectification in heterojunctions with PS3 increases sharply $(K=680-700)$. In our opinion, this is due to desorption of oxygen (or nitrogen) molecules. To prove this, we carried out additional experiments for these heterojunctions, that is, the forward current in heterojunctions at $U=1 \mathrm{~V}$ was measured in the air and in atmospheres of methane and ethanol with various concentrations in a special chamber (Table 2). In this case, the forward current in heterojunctions with PS2 does not change, and in heterojunctions with PS3, it decreases with increasing gas concentration. It is assumed that PS3 heterojunctions can be used as gas sensors. Experiments conducted in various atmospheres on heterojunctions with PS1 showed insignificant changes in current, and heterojunctions with PS2 did not show any change in forward current, i.e., they had stable parameters. This fact suggests that heterojunctions with PS1 and PS2 can be used to manufacture solar cells.

$I-V$ characteristics of heterojunctions with PS1 and PS2 in the semi-log scale and the temperature dependences of the saturation current indicate the presence of a tunnel-recombination mechanism of current through the heterojunctions at forward voltages of up to $0.65 \mathrm{~V}$. It has been established that the I$V$ characteristics of heterojunctions can be represented by the expression

$$
J=J_{0}\left[\exp \left(\frac{e U}{n k T}\right)-1\right]
$$

Here, $J_{0}$ is the saturation current density, $U$ is the applied voltage, $e$ is the electron charge, $n$ is the ideality factor of the current - voltage characteristic, $k$ is the Boltzmann constant, and $T$ is the temperature.

At room temperature, the ideality factors for heterojunctions with PS1 and PS2 were approximately 1.68 and 1.4, respectively (Table 3).

Under standard test conditions of AM1.5 $(W=100 \mathrm{~mW} / \mathrm{cm} 2)$ all the examined samples showed photovoltaic characteristics. The sign of the open circuit photovoltage $(U o c)$ does not change in the entire range of photosensitivity. However, the maximum values of Uoc and short-circuit current (JsC) do not monotonously depend on the pore sizes of silicon. The maximum values of Uoc and Jsc were observed in heterojunctions with PS2 (Fig. 3a).

In this work, the spectral distribution of the photocurrent (Jph) was investigated depending on the pore size of silicon and morphology of CdS films in the wavelength range of 300-1300 nm (Fig. 3b). It was found that the profile of the photocurrent spectrum depends on the pore size and morphology of CdS films. The shortwavelength peak for heterojunctions with PS1 is observed at $510 \mathrm{~nm}$, which corresponds to the band gap of CdS films. Films deposited on silicon with PS1 show microstructural morphology, as evidenced by SEM images. However, the long-wavelength peak of the spectrum at $1125 \mathrm{~nm}$ is due to the absorption of light in $c$-Si. As can be seen from the figure, heterojunctions demonstrate good photosensitivity in the wavelength range of 512-623 nm, which was not observed in the $c-\mathrm{Si} / A^{\prime \prime} B^{\mathrm{VI}}$ heterojunctions without an intermediate PS layer $[4,5]$. It is assumed that the observed sensitivity in PS heterojunctions is associated with the absorption of light in porous silicon. As the pore size increases to $10-16 \mathrm{~nm}$ (PS2), $510 \mathrm{~nm}$ peak shifts to the short-wavelength spectral region, which is associated with the nanostructural properties of CdS films [20,

21]. 
However, an increase of the optical path length in nanostructured films leads to an increase in the degree of light absorption. Therefore, heterojunctions with PS2 show a higher photoelectric conversion efficiency compared to the heterojunctions with PS1 (Table 3). Although it is true that the obtained photoelectric conversion efficiency is relatively low for silicon solar cells, the heterojunctions, we obtained on the basis of a simple and cheap method of electrochemical deposition, expand the prospects of these heterojunctions. It should be noted that the efficiency of photoelectric conversion of solar cells can also be regulated by the PS thickness and thermal annealing regime in various media (air, argon, and hydrogen). We believe that further research in this direction, of course, is promising in terms of improving the efficiency of solar PS cells.

\section{CONCLUSIONS}

Solar cells based on $c$-Si/PS/CdS heterostructures were manufactured by electrochemical deposition. The SEM images confirmed that the morphological properties of CdS films are determined by the PS pore size. It has been shown that the photoelectrical parameters of heterojunctions depend on both the pore sizes of PS and the morphology of CdS films. The maximum photoelectric conversion efficiency of solar cells (7.71\%) was achieved in PS2 heterojunctions. A significant novelty of this work is expressed by the dependence of the values of photoelectrical parameters on the diameters of PS. We believe that this phenomenon can be used in other similar types of heterojunctions and even in hybrid solar cells containing, for example, a perovskite charge separation layer.

\section{REFERENCES}

1. T. Suda and A. Kuroyanagi, J. Cryst. Growth, 61, 494 (1983).

2. T. Hayashi, T. Nishikura, K. Nishimura, and Y. Ema, Jpn. J. Appl. Phys., 28, 1174 (1989).

3. A. K. Katiyar, S. Mukherjee, M. Zeeshan, et al., ACS Appl. Mater. Interfac., 7, 23445 (2015).

4. A. Abdinov, H. Mamedov, H. Hasanov, and S. Amirova, Thin Solid Films, 480-481, 388 (2005).

5. A. Abdinov, H. Mamedov, and S. Amirova, Thin Solid Films, 511-512, 140 (2006).

6. H. Foll, M. Christophersen, J. Carstensen, and G. Hasse, Mate. Sci. Eng. R., 280, 1 (2002).

7. P. Granitzer and K. Rumpf, Materials, 3, 943 (2010).

8. Porous Silicon: From Formation to Application, G. Korotcenkov (ed.), Taylor and Francis Group, CRC Press, USA (2016).

9. V. Y. Yerokhov and I. I. Melnik, Renewable and Sustainable Energy Rev., 3, 291 (1999).

10. A. Ramizy, Z. Hassan, K. Omar, et al., Appl. Surf. Sci., 257, 6112 (2011).

11. E. V. Leonova, D. O. Martynova, and T. I. Izaak, Izv. Vyssh. Uchebn. Zaved. Fiz., 52, No. 12/2, 64, (2009).

12. A. I. Oliva, O. Solis-Canto, R. Castro-Rodriguez, and P. Quintana, Thin Solid Films, 391, 28 (2001).

13. A. Ashour, N. El-Kadry, and S. A. Mahmoud, Thin Solid Films, 269, 117 (1995).

14. A. Ashour, Turk. J. Phys., 27, 551 (2003).

15. S. Keitoku, H. Ezumi, H. Osono, and N. Ohto, Jpn. J. Appl. Phys., 34, 138 (1995).

16. P. Boieriu, R. Sporken, and N. D. Yan Xin, J. Electron. Mater., 29, 718 (2000).

17. A. Abdinov, H. Mamedov, and S. Amirova, Jpn. J. Appl. Phys., 46, 7359 (2007).

18. H. Mamedov, M. Muradov, Z. Konya, et al., J. Solar Energy Eng., 136, 044503-1-4 (2014).

19. H. Mamedov, V. Mamedov, V. Mamedova, and Kh. Ahmadova, J. Optoelectron. Adv. Mater., 17, 67 (2015).

20. M. A. Mahdi, Z. Hassan, S. S. Nig, et al., Thin Solid Films, 520, 3477 (2012).

21. M. Chen, Y. Tang, B. Li, and L. Luo, J. Nanosci. Nanotechnol., 9, 1505 (2009). 


\section{TABLES AND IMAGES}

Table 1.

\begin{tabular}{|c|c|c|c|c|}
\hline Sample & $\begin{array}{c}\text { Anodization } \\
\text { Voltage, } \mathrm{V}\end{array}$ & $\begin{array}{c}\text { Anodization current } \\
\text { density, } \mathrm{mA} / \mathrm{cm}^{2}\end{array}$ & $\begin{array}{c}\text { Anodization } \\
\text { time, } \mathrm{s}\end{array}$ & $\begin{array}{c}\text { Pore } \\
\text { sizes, } \mathrm{nm}\end{array}$ \\
\hline PS1 & 30 & 40 & 1800 & $8-11$ \\
\hline PS2 & 30 & 55 & 1800 & $10-16$ \\
\hline PS3 & 30 & 70 & 1800 & $30-70$ \\
\hline PS4 & 34 & 55 & 1800 & $10-15$ \\
\hline PS5 & 36 & 55 & 1800 & $11-17$ \\
\hline PS6 & 40 & 55 & 1800 & $10-19$ \\
\hline PS7 & 30 & 55 & 1200 & $9-16$ \\
\hline
\end{tabular}

Table 2.

\begin{tabular}{|c|c|c|c|c|c|c|c|c|c|c|c|}
\hline \multirow[t]{2}{*}{$\begin{array}{c}\text { Air } \\
\text { concentration, } \\
\text { ppm } \\
\end{array}$} & \multicolumn{3}{|c|}{$\begin{array}{l}\text { Forward current at } U= \\
\qquad 1 \mathrm{~V}, \mu \mathrm{A}\end{array}$} & \multirow[t]{2}{*}{$\begin{array}{l}\text { Methane } \\
\text { concentra } \\
\text { tion, ppm }\end{array}$} & \multicolumn{3}{|c|}{$\begin{array}{l}\text { Forward current at } \\
\qquad U=1 \mathrm{~V}, \mu \mathrm{A}\end{array}$} & \multirow[t]{2}{*}{$\begin{array}{c}\text { Ethanol } \\
\text { concentration, } \\
\text { ppm } \\
\end{array}$} & \multicolumn{3}{|c|}{$\begin{array}{c}\text { Forward current at } \\
\qquad U=1 \mathrm{~V}, \mu \mathrm{A}\end{array}$} \\
\hline & PS1 & PS2 & PS3 & & PS1 & PS2 & PS3 & & PS1 & PS2 & PS3 \\
\hline 0 & 360 & 1420 & 1180 & 0 & 360 & 1420 & 1180 & 0 & 360 & 1420 & 1180 \\
\hline 50 & 360 & 1421 & 1000 & 65 & 361 & 1421 & 1090 & 70 & 361 & 1421 & 1030 \\
\hline 100 & 365 & 1420 & 760 & 120 & 366 & 1420 & 870 & 150 & 362 & 1421 & 850 \\
\hline 200 & 367 & 1421 & 340 & 250 & 367 & 1421 & 500 & 230 & 365 & 1421 & 430 \\
\hline 300 & 368 & 1420 & 120 & 310 & 366 & 1420 & 360 & 300 & 365 & 1421 & 280 \\
\hline
\end{tabular}

Table 3. Electrical and Photoelectrical Parameters of Heterojunctions Depending on the Pore Sizes in PS

\begin{tabular}{|c|c|c|c|c|c|c|}
\hline Samples & $\begin{array}{c}\text { Ideality } \\
\text { factor }\end{array}$ & $\begin{array}{c}\text { Rectification } \\
\text { coefficient K }\end{array}$ & $\mathrm{U}_{\mathrm{oc}}, \mathrm{mV}$ & $\mathrm{J}_{\text {sc., }} \mathrm{mA} / \mathrm{cm}^{2}$ & $\mathrm{FF}$ & $\eta, \%$ \\
\hline c-Si/PS1/CdS & 1.68 & 180 & 482 & 15.7 & 0.53 & 4.01 \\
\hline c-Si/PS2/CdS & 1.4 & 1100 & 557 & 21.3 & 0.65 & 7.71 \\
\hline
\end{tabular}

Fig. 1. SEM-images of the porous silicon PS2 $(a)$ and CdS films deposited on the surface of the PS2 substrate $(b)$. 

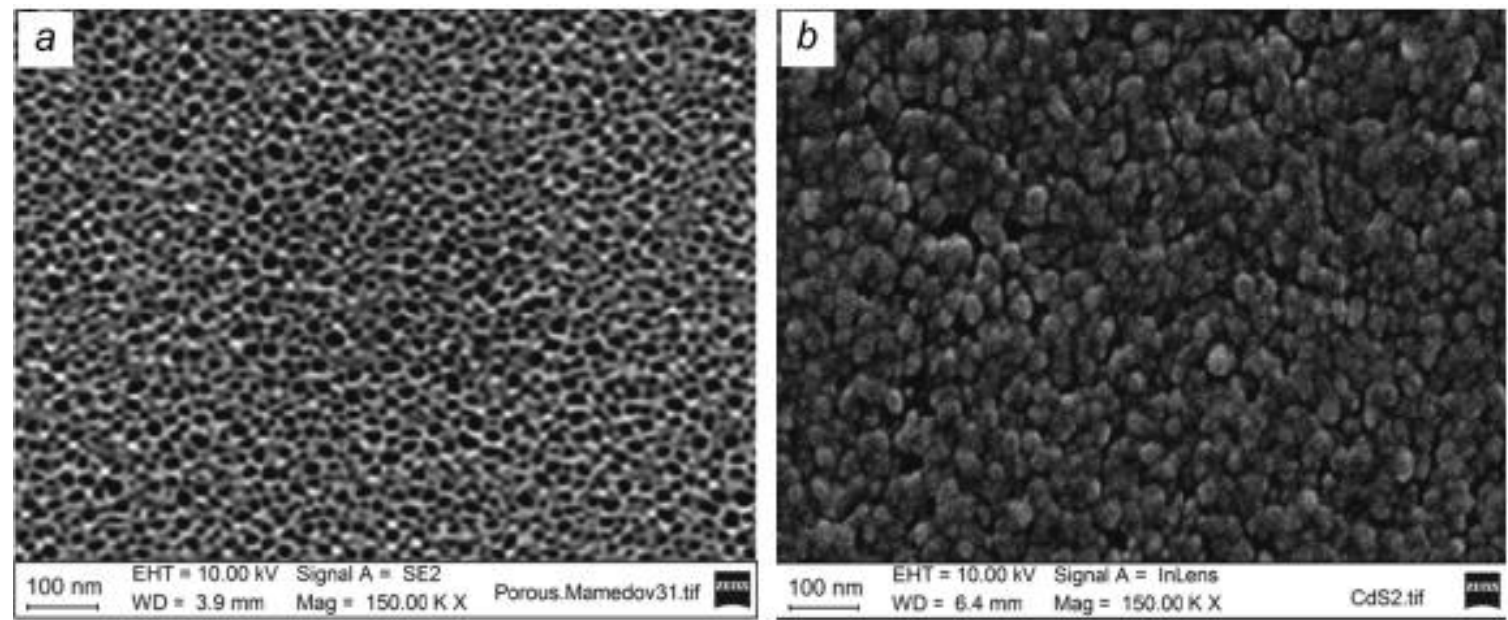

Fig. 2. I- $V$ characteristics of $c-S i / P S / C d S$ heterojunctions directly after deposition $(a)$ and after annealing in vacuum at $70^{\circ} \mathrm{C}(b)$.
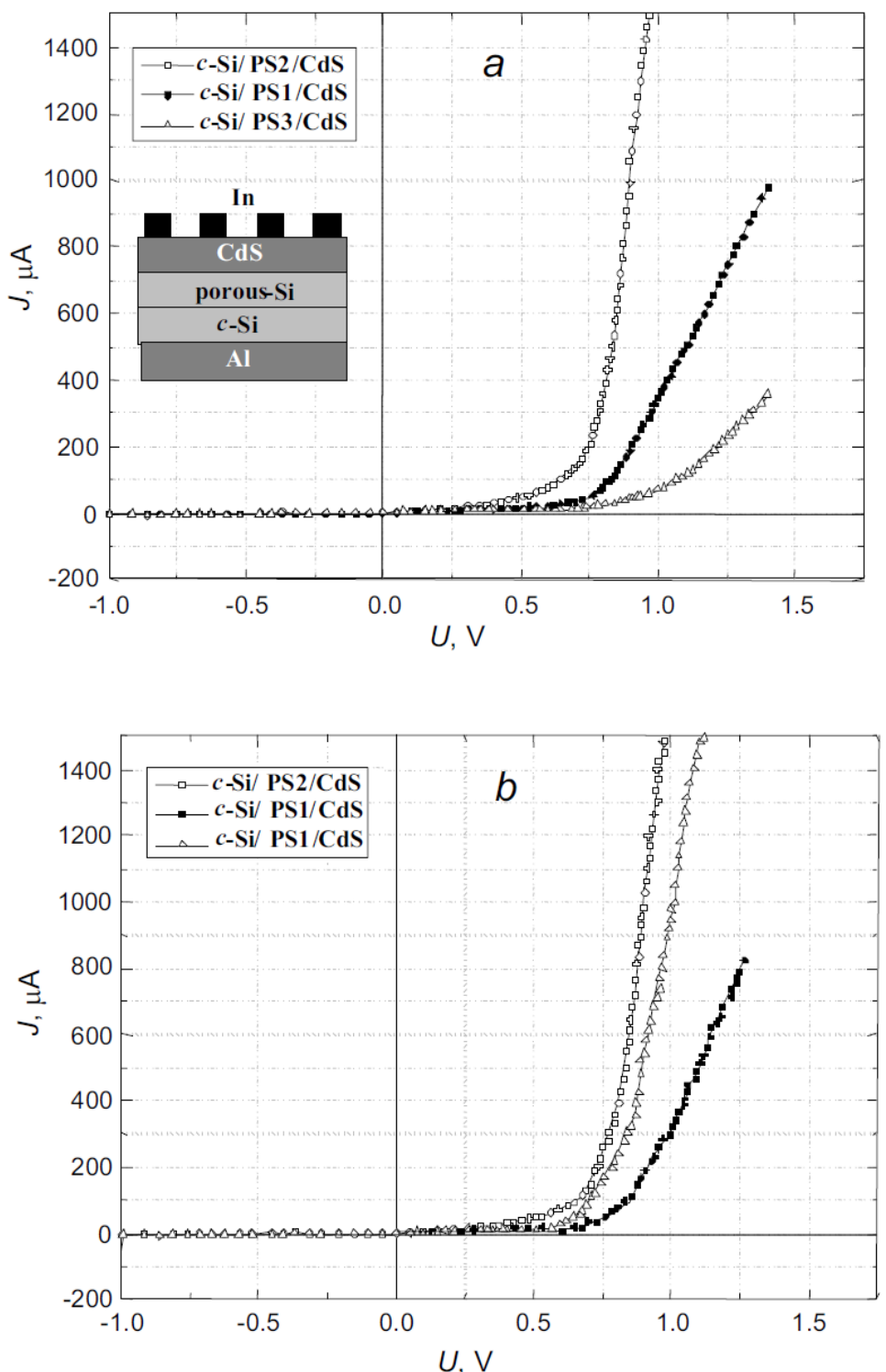

Fig. 3. Dependences of Uoc and Jsc on the pore size in silicon $(a)$ and spectral distribution of photocurrent in $c$-Si/PS/CdS heterojunctions (b). 

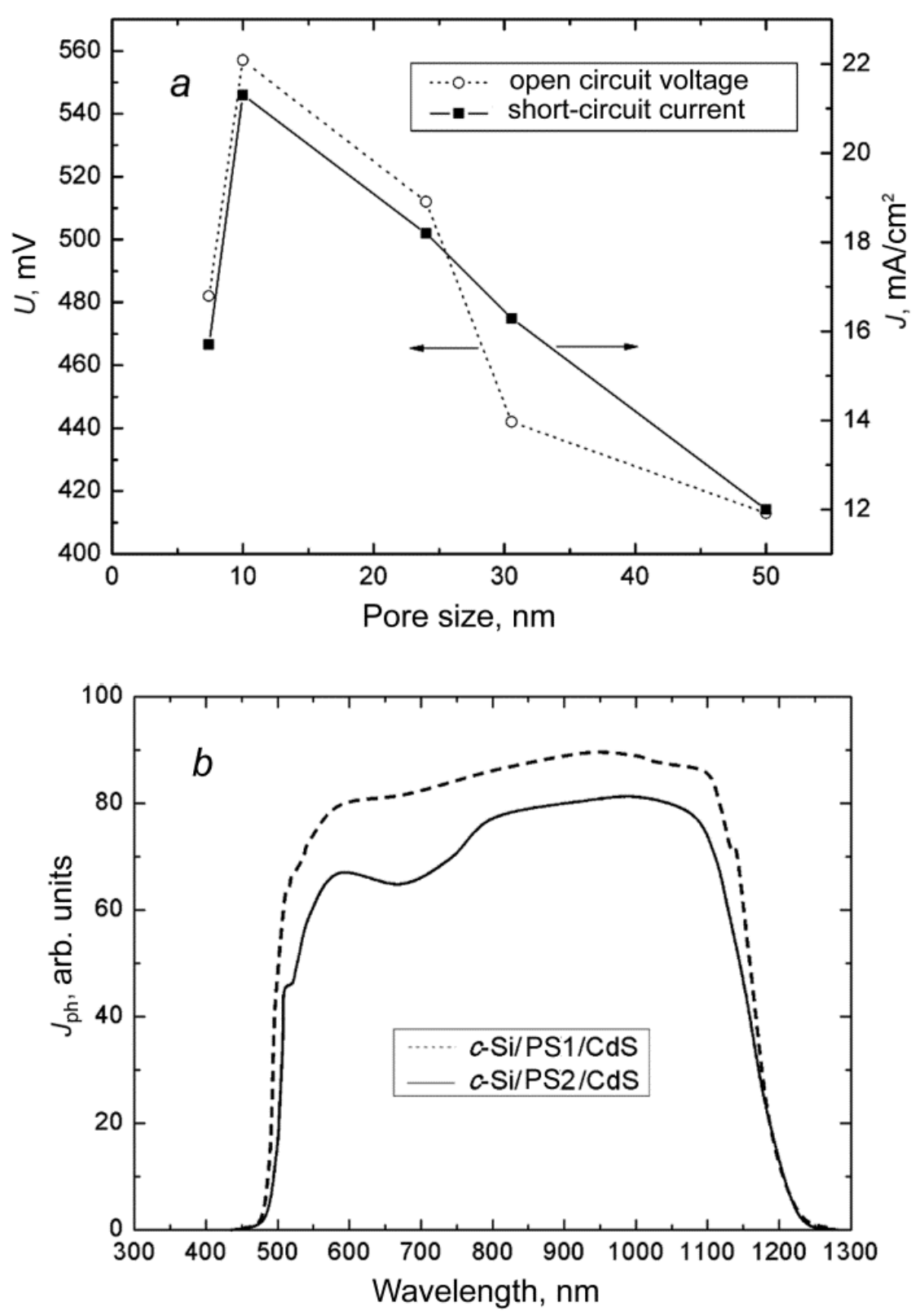